\title{
Prevalência da infecção pelos vírus das hepatites A e E em escolares de município da Amazônia Matogrossense
}

\author{
Prevalence of hepatitis A and E virus infection in school children \\ of an Amazonian municipality in Mato Grosso State
Sandra Breder Assis', Francisco José Dutra Souto', Cor Jesus Fernandes Fontes ${ }^{1}$ e Ana Maria Coimbra Gaspar ${ }^{2}$

\begin{abstract}
Resumo Avaliou-se a prevalência de anticorpos para as hepatites A e E em 487 crianças de 2 a 9 anos, de um município da Amazônia matogrossense. As prevalências de anti-VHA e anti-VHE foram 86,4\% (IC95\% $83-89,3)$ e 4,5\% (IC95\% 2,9-6,9) respectivamente. A prevalência de anti-VHA já se mostrou elevada desde as faixas etárias mais baixas, distribuição típica das regiôes de alta endemicidade da doença. Não se constatou associação de prevalência de marcadores das hepatites $A$ e E com gênero, classe sócio-econômica, escolaridade dos pais, condições higiênicas, número de moradores por residência, densidade de moradores por cômodo e entre as escolas estudadas. A prevalência de hepatite E foi baixa, semelhante às encontradas entre adultos em outras regiões do Brasil.
\end{abstract}

Palavras-chaves: Hepatite A. Hepatite E. Epidemiologia. Amazônia Crianças.

Abstract The prevalence of antibodies to hepatitis A anti-HAV total and E viruses anti-HEV IgG was assessed in 487 children ranging from 2 to 9 years old who were students of nurseries and public schools in a county of the Amazonian region, in Mato Grosso State, Brazil. The anti-HAV and anti-HEV prevalence were $86.4 \%$ (Cl 95\% $83-89.3)$ and 4.5\% (C195\% $2.9-6.9)$, respectively. The anti-HAV prevalence was high in all ages, suggesting that this is an area of high endemicity for HAV infection. There was no association between the antiHAV markers and gender, socioeconomic level, parental educational level, hygienic conditions, number or density of residents per room or schools in which they studied. Anti-HEV prevalence was low and similar to that found among adults in another Brazilian regions.

Key-words: Hepatitis A. Hepatitis E. Epidemiology. Amazon Children.

As hepatites virais são um importante problema de saúde pública em todo o mundo. Podem ser divididas, considerando-se as vias de transmissão, sexual e parenteral e a via entérica. São bem conhecidas nesse último grupo as hepatites por vírus $\mathrm{A}(\mathrm{VHA})$ e por vírus $\mathrm{E}(\mathrm{VHE})$.

Enquanto a hepatite $A$ tem distribuição universal, a hepatite $\mathrm{E}$ distribui-se irregularmente pelo mundo. Ocorre raramente nos países desenvolvidos, geralmente em indivíduos que viajaram recentemente para áreas endêmicas. Pode ocorrer de forma esporádica nos países de regiões tropicais e subtropicais em desenvolvimento, ou em forma de epidemias como as do México e Índia ${ }^{11}$.
Na América Latina e no Brasil, estudos sobre o VHA têm demonstrado que a prevalência da exposição ao agente começa a sofrer um desvio de alta para média prevalência, em conseqüência da melhoria das condições sanitárias ${ }^{21016}$. No entanto, ainda há grande variação regional, com a prevalência sendo maior no norte do Brasil, quando comparado às regiões Sul e Sudeste 2 . Quanto ao VHE, os poucos estudos nacionais em grupos específicos particulares, como garimpeiros, pacientes de hemodiálise e casos de hepatite aguda, verificaram prevalência variando de $3 \%$ a $6 \%{ }^{489}$. Um único estudo de base populacional, com amostra aleatória, demonstrou presença de anticorpos lgG (anti-VHE) em 3,3\% da população estudada ${ }^{15}$.

\footnotetext{
1. Departamento de Pediatria e Clínica Médica da Faculdade de Medicina da Universidade Federal do Mato Grosso. 2. Laboratório de Desenvolvimento Tecnológico do Departamento de Virologia da Fundação Oswaldo Cruz, Rio de Janeiro, RJ.

Endereço para correspondência: Dra. Sandra Breder Assis. Dept ${ }^{\circ}$ de Pediatria/Hospital Universitário Júlio Muller. Rua L s/n, Bairro Alvorada, 78048-000 Cuiabá, MT.

Telefax: $5565615-7320$

E-mail:sandrassis@terra.com.br

Recebido para publicação em 30/1/2001.
} 


\section{MATERIAL E MÉTODOS}

No final de 1998, realizou-se inquérito soroepidemiológico no município de Peixoto de Azevedo, localizado na latitude $-10^{\circ} 13^{\prime} 12^{\prime \prime}$ e longitude $-54^{\circ} 58^{\prime} 08^{\prime \prime}$ no norte do Mato Grosso e sul da bacia amazônica, visando a identificação da prevalência e fatores de risco associados à infecção pelos vírus das hepatite $\mathrm{A}$ e $\mathrm{E}$. Apenas crianças menores de 10 anos constituíram a população de estudo, uma vez que levantamento anterior realizado por pesquisadores deste grupo, já havia avaliado a situação epidemiológica das hepatites virais nas crianças a partir de $10 \operatorname{anos}^{15}$. A escolha do município de Peixoto de Azevedo se deu pelo fato de estar localizado numa região do Estado onde foram notificados grande número de casos de hepatite, não identificados sorologicamente, durante o ano de 1997 e 1998.

Foi obtida amostra, por sorteio aleatório sistemático, de $591(25,3 \%)$ crianças entre as 2.335 de 2 a 9 anos, matriculadas durante o ano de 1998, nas 14 creches e escolas públicas do município. Foram estudadas 487 crianças, sendo $255(52,4 \%)$ do sexo feminino. Os responsáveis que concordaram com a participação, assinaram termo de consentimento e foram entrevistados para obtenção de informações sobre condições higiênico-sanitárias da família (origem e, tratamento domiciliar da água, destino do lixo, tipo de esgotamento dos dejetos, hábitos de higiene pessoal), nível sócio-econômico (número e tipo de eletrodomésticos que a família possuía), número de moradores por residência, profissão e grau de escolaridade dos pais. O protocolo deste estudo foi aprovado pelo Comitê de Ética em Pesquisa do Hospital Universitário Júlio Muller - UFMT (no 04/1998).

As crianças tiveram $5 \mathrm{ml}$ de sangue coletado em veia cubital e as amostras de sangue foram encaminhadas para o Departamento de Virologia da FIOCRUZ, Rio de Janeiro, onde foram testadas para a presença de antiVHA total e anti-VHE da classe IgG utilizando testes imunoenzimáticos, sendo que para a pesquisa do antiVHA utilizamos um kit in house com sensibilidade e especificidade $>95 \%$ em relação aos testes comerciais disponíveis no mercado e para pesquisa do anti-VHE o teste comercial da Abbot Laboratories, North Chicago, IL.

O estudo foi analisado como caso-controle, utilizando-se o Teste t de Student para a diferença das médias, teste exato de Fisher para proporções que ocorreram com baixa freqüência e Odds-ratios com intervalos de confiança de 95\%, considerando-se nível de significância de $5 \%$.

\section{RESULTADOS}

Na população estudada, 85,6\% (417) das famílias possuíam de 3 a 5 eletrodomésticos, $50,7 \%$ (242) das mães e $54,5 \%$ (244) dos pais estudaram até a 4⿳亠丷厂 série do ensino fundamental. A média de cômodos utilizados para dormir foi de 2,3. Água encanada estava disponível em $65,5 \%$ (295) dos domicílios estudados, embora 19,2\% (79) se utilizassem também dos poços que faziam o abastecimento de água antes da inauguração do sistema canalizado, cerca de um ano antes do início da coleta destes dados. Cento e oitenta e cinco (38\%) famílias utilizavam água de poço. Em $24,4 \%$ (143) domicílios a água era consumida diretamente da torneira ou poço sem nenhum tratamento prévio e $29,6 \%$ (144) filtravam a água para beber. Fossa seca para esgotamento dos dejetos foi referida por $51 \%$ (250) indivíduos e fossa negra por $45,8 \%$ (223). Não existe sistema de esgotamento de dejetos no município. O lixo era recolhido pela prefeitura em $81,1 \%$ (395) dos domicílios.

Hepatite A: A soroprevalência da infecção pelo VHA entre os escolares estudados foi de $86,4 \%$
(IC95\%: 83,0 - 89,3), sendo semelhante entre os sexos masculino $(46,8 \%)$ e feminino $(53,2 \%)$ $(p=0,30)$. A Tabela 1 mostra a elevação constante dos níveis de anti-VHA em relação à idade. Nível sócio-econômico, condições higiênicas e sanitárias, número de moradores no domicílio e nível de escolaridade dos pais não se associaram a maior prevalência de anti-VHA. Não houve diferenças estatisticamente significantes das prevalências de anti-VHA entre as 14 escolas estudadas.

Hepatite E: A soroprevalência global de anticorpos anti-VHE encontrada entre as crianças foi de $4,5 \%$ (IC95\%: 2,9-6,9). Esta taxa assemelha-se à de estudos realizados entre adultos no Brasil ${ }^{4} 8$ 15. A distribuição foi semelhante nos dois sexos $(p=0,30)$. Em relação à faixa etária, não se observou variação estatisticamente significante das prevalências de anticorpos (Tabela 1). Semelhantemente à hepatite A, não se encontrou maior prevalência de anti-VHE IgG associada às variáveis estudadas ou às diferentes escolas.

\section{DISCUSSÃO}

A elevada prevalência de hepatite $A$, já na primeira década da vida, é característica das populações de baixo nível sócio-econômico e condições higiênico sanitárias precárias. Avaliação patrimonial pela escala sócio-econômica da ABIPEME ${ }^{5}$, através de questionário, situou a média da população desta amostra na classe $D$.
O aumento crescente da prevalência de marcadores de VHA com a faixa etária, segue o padrão das doença infecciosas em geral, em que o risco de infecção aumenta proporcionalmente com o tempo de exposição. A alta prevalência de marcador de infecção pelo VHA aqui observada é preocupante, considerando-se a possibilidade, mesmo que rara, da evolução da hepatite 
Tabela 1 - Prevalência e Intervalo de Confiança de 95\% dos anticorpos totais da classe IgG contra os vírus das hepatites $A$ e $E$ respectivamente entre escolares de 2 a 9 anos segundo idade (Peixoto de Azevedo, MT - 1998).

\begin{tabular}{|c|c|c|c|c|c|c|c|c|}
\hline \multirow{2}{*}{$\begin{array}{l}\text { Idade } \\
\text { (anos) }\end{array}$} & \multirow{2}{*}{$\begin{array}{c}\text { Indivíduos } \\
\text { noo }\end{array}$} & \multicolumn{3}{|c|}{ Anti-VHA (+) } & \multirow[b]{2}{*}{$\mathrm{OR}^{*}$} & \multicolumn{3}{|c|}{ Anti-VHE (+) } \\
\hline & & $n^{0}$ & $\%$ & IC 95\% & & $\mathrm{n}^{0}$ & $\%$ & IC 95\% \\
\hline 3 & 8 & 5 & 62,5 & $25,9-89,8$ & 1,0 & 0 & & \\
\hline 4 & 13 & 10 & 76,9 & $46,0-93,8$ & 2,0 & 0 & & \\
\hline 5 & 48 & 38 & 79,2 & $64,6-89,0$ & 2,3 & 5 & 10,4 & $3,9-23,4$ \\
\hline 6 & 87 & 74 & 85,0 & $75,4-91,5$ & 3,4 & 5 & 5,7 & $2,1-13,5$ \\
\hline 7 & 106 & 92 & 86,8 & $78,5-92,3$ & 3,9 & 1 & 0,9 & $0,0-5,9$ \\
\hline 8 & 124 & 111 & 89,5 & $82,4-94,1$ & 5,1 & 8 & 6,4 & $3,0-12,7$ \\
\hline 9 & 101 & 91 & 90,1 & $82,1-94,9$ & 5,5 & 3 & 3,0 & $0,8-9,1$ \\
\hline Total & 487 & 421 & 86,4 & $83,0-89,3$ & - & 22 & 4,5 & $2,9-6,9$ \\
\hline
\end{tabular}

* OR ajustada por idade quanto ao anti-VHA

Qui-quadrado de tendência: 7,7 $(p<0,01)$.

aguda $A$ para a insuficiência hepática fulminante. De fato, estudo realizado na Argentina mostrou que o VHA foi o agente causador de $64 \%$ dos casos de hepatite aguda em crianças que evoluíram para insuficiência hepática fulminante e transplante de fígado'.

A prevalência de marcadores do VHE $(4,5 \%)$ foi

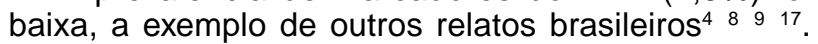
Como só foram incluídas crianças no presente estudo, é provável que a população geral de Peixoto de Azevedo possa ter prevalência total maior que outras localidades brasileiras. Portanto, presume-se que o VHE tem baixa circulação nesta localidade, visto que as condições favoráveis à transmissão dos vírus entéricos estão presentes, como comprova a alta prevalência do VHA. A abundância de recursos hídricos na Amazônia pode funcionar como fator limitante da transmissão do VHE, já que epidemias só foram relatadas em situação de maciça contaminação do abastecimento restrito de água por esgoto ou, em regiões rurais, por contaminação de fontes de água partilhadas por muitos indivíduos ${ }^{3712}$.

Diferentemente das populações urbanas das regiões mais desenvolvidas do Brasil, as populações rurais amazônicas ainda estão altamente expostas aos agentes infecciosos de transmissão entérica. A melhoria das condições de higiene, fornecimento de água de boa qualidade, programas educativos populacionais, seriam as soluções, em longo prazo para diminuir a prevalência dessas infecções. Já se demonstrou que a vacinação contra o VHA é um meio efetivo de controle de surtos de hepatite $A$ e que a relação custo-benefício é compensadora ${ }^{613}$. No entanto, a vacinação das crianças, contra esta virose antes dos 3 anos de idade, embora seja a estratégia preferencial para quebrar a cadeia de transmissão contínua de infecção pelo VHA, requer um montante elevado de recursos, que não tem encontrado justificativa diante da benignidade da grande maioria dos casos desta virose na infância. Por exemplo, das 416 crianças com anti-HAV IgG positivos nesta amostra, apenas $24(5,8 \%)$ tinham histórico de hepatite clínica.

Quanto ao VHE, estudos que identifiquem a presença do genoma viral ainda são necessários para confirmar a circulação deste agente em nosso meio. As baixas prevalências verificadas no presente estudo, e em outros acima referidos, sugerem que o VHE não é, pelo menos até agora, um problema importante no Brasil. A presença de anticorpos anti-VHE em quase todas as populações brasileiras investigadas, mesmo que em baixa freqüência sugere que uma amostra de HEV não patogênica para o homem possa estar circulando e que provavelmente possa ser em animais como já anteriormente descrito em outras regiões do mundo consideradas não endêmicas ${ }^{14}$.

\section{REFERÊNCIAS BIBLIOGRÁFICAS}

1. Ciocca M, Ramonet M, Cuarterolo M, Sashon J, Garcia de Davilla MT, Albano L, Speranza AM, Morise S, Gomez S, Debbag R, Imventarza O, Garrahan JP. Fulminant hepatic failure due to viral hepatitis in children. In: Abstract of proceedings $9^{\text {th }}$ Triennial International Symposium, on Viral Hepatitis and Liver Disease, Rome, p. A310, 1996.

2. Clemens SAC, Fonseca JC, Azevedo T, Cavalcanti A, Silveira TR, Castilho MC, Clemens R. Soroprevalência para hepatite A e hepatite B em quatro centros do Brasil. Revista da Sociedade Brasileira de Medicina Tropical 33:1-10, 2000.

3. Corwin AL, Khiem HB, Clayson ET, Sac PK, Nhung VT, Yen VT, Cuc CT, Vaughn D, Merven J, Richie TL, Putri MP, He J, Graham R, Wignall FS, Hyams KC. A waterborne outbreak of hepatitis $E$ virus transmission in southwestern Vietnam . American Journal of Tropical Medicine and Hygiene 54: 559-562, 1996.

4. Focaccia R, Sette Jr H, Conceição, OJG. Hepatitis E in Brazil. Lancet 346:1165,1995.

5. Galduróz JCF, Noto AR, Carlini EA. IV Levantamento sobre uso de drogas entre estudantes de $1^{\circ}$ e $2^{\circ}$ graus em 10 capitais brasileiras. Universidade federal de São Paulo - Departamento de Psicologia- Centro Brasileiro de Informações Sobre Drogas Psicotrópicas. Anexo VI: Esclarecimento sobre a escala sócioeconômica da ABIPEME São Paulo, 1977.

6. Lucioni C, Cipriani V, Mazzi S, Panuzio M. Cost of an outbreak of hepatitis A in Publia, Italy. Pharmacoeconomics 13: 127266, 1998. 
7. McCarthy MC, He J, Hyams KC, El-Tigani A, Khalid IO, Carl M. Acute hepatitis E infection during the 1988 floods in Khartoum, Sudan. Transaction of Royal Society of Tropical Medicine and Hygiene 88: 177, 1994.

8. Pang L, Alencar FEC, Cerutti Jr C, Milhous WK, Andrade AL, Oliveira R, Kanesa-Thasan N, Macarthy PO, Hoke Jr CH. Hepatitis E infection in the Brazilian Amazon. American Journal of Tropical Medicine and Hygiene 52:347-348, 1995.

9. Paraná R, Cotrim HP, Cortey-Boennec ML, Trepo C, Lyra LGC. Prevalence of hepatitis $E$ virus IgG antibodies in patients from a referral unit of liver diseases in Salvador, Bahia, Brazil. American Journal of Tropical Medicine and Hygiene 57: 60-61, 1997.

10. Pinho JR, Sumita LM, Moreira RC, Souza VA, Saraceni CP, Carvalho MC, Pannuti CS. Duality of patterns in hepatitis A epidemiology: a study involving two socioeconomically distinct populations in Campinas, São Paulo State, Brazil. Revista do Instituto de Medicina Tropical de São Paulo 40: 105-106, 1998.

11. Purcell, HR e Emerson, SU. Hepatitis E virus. In: Principles and Practice of Infectious Diseases. Philadelphia: Mandell, Douglas and Bennett's Publishers 2:1958-1970, 2000.

12. Rab MA, Bile MK, Mubarik MM, Asghar H, Sami Z, Siddiqi S, Dil AS, Barzgar MA, Chaudhry MA, Burney MI. Water-borne hepatitis E virus epidemic in Islamabad, Pakistan: a common source outbreak traced to the malfunction of a modern water treatment plant. American Journal of Tropical Medicine and Hygiene 57: 151-157, 1997.

13. Sagliocca L, Amoroso P, Stroffolini T, Adamo B, Tosti ME, Lettieri G, Esposito C, Buonocore S, Pierri P, Mele A. Efficacy of hepatitis $A$ vaccine in prevention of secondary hepatitis $A$ infection: a randomised trial. Lancet 353: 1136-1139, 1999.

14. Seow H, Mahomed NMB, Mak J, Ridell MA Li F, Anderson DA 1999. Seroprevalence of antibodies to hepatitis $E$ virus in the normal blood population general population and two aboriginal communities in Malaysia. Journal of Medical Virology 59:164-168,1999.

15. Souto FJD, Fontes CJF. Prevalence of IgG-class antibodies against hepatitis $E$ virus in a community of the southern Amazon: a randomized survey. Annals of Tropical Medicine and Pharmacology 92: 623-625, 1998.

16. Vitral CL, Yoshida CF, Lemos ER, Teixeira CS, Gaspar AM. Agespecific prevalence of antibodies to hepatitis $A$ in children and adolescents from Rio de Janeiro, Brazil, 1978 and 1995. Relationship of prevalence to environmental factors. Memórias do Instituto Oswaldo Cruz 93: 1-5, 1998.

17. Trinta KS, Liberto MI, de Paula VS, Yoshida CF, Gaspar AM. Hepatitis $E$ virus infection in selected Brazilian population. Memórias do Instituto Oswaldo Cruz, 96:5-29, 2001. 